\title{
Effect of autophagy inhibition on cell viability and cell cycle progression in MDA-MB-231 human breast cancer cells
}

\author{
QIUJUN LIU $^{1,2}$, XINLI SHI $^{3}$, XIANYAO ZHOU $^{1}$, DA WANG $^{1}$, LI WANG $^{4}$ and CHANGLONG LI ${ }^{1}$ \\ ${ }^{1}$ Department of Biochemistry and Molecular Biology, West China School of Preclinical and Forensic Medicine, \\ Sichuan University, Chengdu, Sichuan 610041; ${ }^{2}$ Department of Biochemistry, Luzhou Medical College, Luzhou, \\ Sichuan 646000; ${ }^{3}$ Department of Pathobiology and Immunology, Hebei University of Traditional Chinese Medicine, \\ Shijiazhuang, Hebei 050200; ${ }^{4}$ Research Center of Traditional Chinese and Western Medicine, \\ Affiliated Traditional Hospital, Luzhou Medical College, Luzhou, Sichuan 646000, P.R. China
}

Received January 6, 2014; Accepted May 22, 2014

DOI: $10.3892 / \mathrm{mmr} .2014 .2296$

\begin{abstract}
Atg7 is an autophagy-related gene, and is involved in two ubiquitin-like conjugation systems in the process of autophagy. It is well established that 3 -methyladenine (3Ma) is an autophagy inhibitor. The present study aimed to investigate the effect of autophagy inhibition on the cell viability and cell cycle progression of human breast cancer cells. MDA-MB-231 human breast cancer cells were cultured in Dulbecco's modified Eagle's medium (DMEM) with high glucose, then divided into six groups. The six groups included the three fundamental groups as follows: The control group (untreated); the starvation group (high-glucose DMEM replaced with glucose-free minimal essential medium); and the starvation 3Ma group (maintained in glucose-free culture medium and treated with the autophagy inhibitor $3 \mathrm{Ma}$ ). The three fundamental groups were further divided into Atg7 siRNA-transfected and non-transfected groups. The cell viability and apoptosis of each group was determined by MTT assay and flow cytometry. The results of the current study demonstrated that Atg7 deficiency alone had no statically significant effect on the cell viability of MDA-MB-231 human breast cancer cells, while $3 \mathrm{Ma}$ reduced the cell viability and its effect was potentiated by Atg7 deficiency. Atg7 deficiency was more intense than 3Ma in the promotion of apoptosis and cell arrest in $\mathrm{G}_{0} / \mathrm{G}_{1}$-phase in the absence of glucose and its effect was reduced by $3 \mathrm{Ma}$. In conclusion, 3Ma and Atg7 may be involved in different pathways in the process of autophagy. Inhibition of autophagy
\end{abstract}

Correspondence to: Professor Changlong Li, Department of Biochemistry and Molecular Biology, West China School of Preclinical and Forensic Medicine, Sichuan University, no. 17, Section Three, Ren Min Nan Road, Chengdu, Sichuan 610041, P.R. China

E-mail: changlongli@scu.edu.cn

Key words: autophagy inhibition, Atg7 deficiency, 3-methyladenine, breast cancer, MDA-MB-231 cells, cell cycle may influence the cell viability and cell cycle through different pathways in MDA-MB-231 human breast cancer cells.

\section{Introduction}

Autophagy is a conserved process (1-3) that degrades the cytoplasmic contents with lysosomal enzymes (4-7). It is a physiological function required for normal animal development and survival in metabolic stress. The autophagy program is activated when the organism suffers stress due to starvation. Recent studies indicate that autophagy has important implications during cancer initiation and progression. Autophagy functions as a protective mechanism. This mechanism (8-10) is utilized by normal cells and cancer cells, so autophagy is considered to have varied roles in the development and treatment of cancer (11-13). There are two ubiquitin-like conjugation systems for autophagy, the Atg12 and Atg8 conjugation systems. Atg7 is important in the process of autophagy as this E1 enzyme can activate Atg12 and Atg8. Currently, it is unclear how Atg7 functions in breast cancer. It is well established that 3-methyladenine (3Ma) (14-16) is an autophagy depressor. However, little is understood regarding the effect of autophagy inhibition on cell viability and the cell cycle in breast cancer, or if the mechanisms of 3Ma and Atg7 are associated. In order to investigate the effect of autophagy inhibition on MDA-MB-231 human breast cancer cells in the present study, different cell models were designed and the changes in the cell cycle and viability of the cells were assessed by flow cytometry and MTT assay, respectively.

\section{Materials and methods}

Cell culture and model establishment. MDA-MB-231 human breast cancer cells were cultured at $37^{\circ} \mathrm{C}$ in high-glucose Dulbecco's modified Eagle's medium (DMEM) (Gibco-BRL, Carlsbad, CA, USA) with $10 \%$ fetal bovine serum, $100 \mathrm{U} / \mathrm{ml}$ penicillin and $100 \mu \mathrm{g} / \mathrm{ml}$ streptomycin (Gibco-BRL). All cultures were maintained at $37^{\circ} \mathrm{C}$ in a humidified atmosphere with $5 \% \mathrm{CO}_{2}$. When cells reached $\sim 80 \%$ confluence, cells were seeded into 96 -well plates at a density of $1.0 \times 10^{4}$ cells/well to a total of $200 \mu 1 /$ well and 
were incubated for $24 \mathrm{~h}$ in routine culture. They were then divided into groups. The three groups without Atg7 siRNA transfection were as follows: The control (untreated) group; the starvation (S) group (replaced high-glucose DMEM with no-glucose minimal essential medium and maintained for $4 \mathrm{~h}$ ); and the S+3Ma group (starvation group treated with $0.05 \mathrm{mM} / 13 \mathrm{Ma}$ ). The other three groups were obtained by transfecting Atg7 siRNA into half the cells of each of the three fundamental groups, and were denoted as follows: The Atg7(-) group (controls with Atg7-siRNA transfection); the S+Atg7(-) group (starvation group treated with Atg7-siRNA); and the $\mathrm{S}+\mathrm{Atg} 7(-)+3 \mathrm{Ma}$ group (starvation group treated with $0.05 \mathrm{mM} / 13 \mathrm{Ma}$, following transfection with Atg7-siRNA for $4 \mathrm{~h}$ ). Each group was repeated in three different wells under identical conditions.

Atg7 siRNA transfection. In the Atg7-deficiency models, Atg7 siRNA (RiboBio, Guangzhou, China) was transfected into the corresponding groups with Lipofectamine ${ }^{\mathrm{TM}}$ RNAiMAX Transfection reagent (Invitrogen, Life Technologies, Carlsbad, CA, USA). Isolation of total RNA and cDNA synthesis were performed with TRIzol ${ }^{\circledR}$ reagent and a cDNA Synthesis kit purchased from Takara Biotechnology (Dalian, China). All steps were implemented in accordance with the manufacturer's instructions. The Atg7 mRNA levels were detected by quantitative polymerase chain reaction (qPCR) and transfection efficiency reached $>70 \%$. The sequences of the Atg7 primers [Sangon Biotech (Shanghai) Co.,Ltd., Shanghai, China] were as follows: Human Atg7: F, 5'-CTTTTTGCCAACATCCCTG-3' and R, 5'-GGTCTCTGGTTGAATCTCCT-3'; human $\beta$-actin primers: F, 5'-GAAGATCAAGATCATTGCTCCT-3' and R, 5'-TACTCCTGCTTGCTGATCCA-3'. qPCR reaction conditions were as follows: $2 \mathrm{~min}$ at $94^{\circ} \mathrm{C}, 40$ cycles of $20 \mathrm{sec}$ at $94^{\circ} \mathrm{C}, 16 \mathrm{sec}$ at $54^{\circ} \mathrm{C}$ and $30 \mathrm{sec}$ at $72^{\circ} \mathrm{C}$. The control group was transfected with negative-control siRNA. Following transfection for $4 \mathrm{~h}$, the medium was removed from all groups and the cells were washed twice with $0.01 \mathrm{~mol} / 1$ phosphate-buffered saline (PBS). The cells were then recultured in high-glucose DMEM. The morphological changes in the cells were observed with an inverted microscope at $24 \mathrm{~h}$ after transfection (Eclipse TE2000-E; Nikon, Tokyo, Japan).

Cell viability assay. Cell viability was measured by MTT (M-2128; Sigma-Aldrich, St. Louis, MO, USA) method according to the manufacturer's instructions. All groups were detected at 6, 12, 24, 48 and 72-h time points.

Flow cytometry assay. MDA-MB-231 cells were seeded into 6 -well plates at a density of $5 \times 10^{4}$ cells $/ \mathrm{ml}$ with a total of $2 \mathrm{ml} /$ well then treated individually based on the aforementioned groups. The cells were harvested after $24-\mathrm{h}$ incubation, and then they were fixed in $70 \%$ precooled ethanol for $1 \mathrm{~h}$. Following two washes with PBS, the cells were centrifuged and resuspended in $1 \mathrm{ml} \mathrm{PBS}(0.01 \mathrm{~mol} / \mathrm{l})$, then stored at $4^{\circ} \mathrm{C}$ overnight. The cells were stained in PBS containing $50 \mu \mathrm{g} / \mathrm{ml}$ RNase and $100 \mu \mathrm{g} / \mathrm{ml}$ propidium iodide in the dark at room temperature for $30 \mathrm{~min}$. Flow cytometry (FACSCanto II; BD Biosciences, San Jose, CA, USA) was used to analyze the cell cycle and levels of apoptosis with BD FACSDiva software (BD Biosciences).

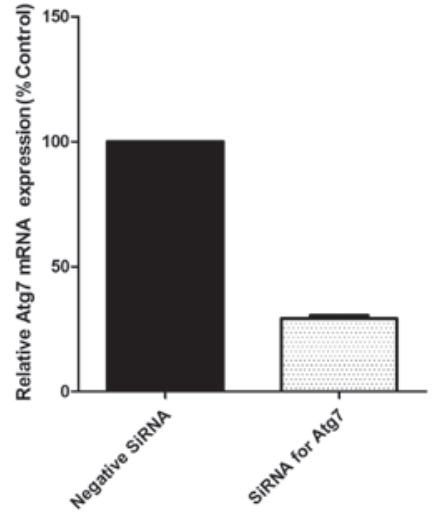

Figure 1. Comparison of Atg7 mRNA expression prior to and following Atg7 interference. The measurements of Atg7 mRNA expression were repeated 12 times independently by qPCR with $\beta$-actin as the reference gene. Transfection efficiency reached $>70 \%$. Data are expressed as the mean \pm standard deviation. qPCR, quantitative polymerase chain reaction.

Statistical analysis. All data were analyzed using GraphPad Prism software, version 5.01 (GraphPad, San Diego, CA, USA). The cell viability detected by the MTT method was assessed by two-way repeated measures analysis of variance with Bonferroni post-hoc tests. $\mathrm{P}<0.05$ was considered to indicate a statistically significant difference. The data are expressed as the mean \pm standard deviation of experiments performed in triplicate.

\section{Results}

Transfection efficiency. The measurement of Atg siRNA transfection efficiency was repeated 12 times independently by qPCR with $\beta$-actin. Relative Atg7 mRNA expression levels are presented in Fig. 1 compared with levels in the control group, and the transfection efficiency reached $>70 \%$.

Cytomorphological changes vary between groups inhibited by $3 \mathrm{Ma}$ and groups with Atg7 deficiency. Following 24-h transfection with Atg7 siRNA, the cells exhibited more protuberances. In addition, the cells congregated and adhered to the wall of the culture plate more easily [control vs. $\operatorname{Atg} 7(-) ; S$ vs. S+Atg7(-); S+3Ma vs. S+Atg7(-)+3Ma]. On the contrary, in the $\mathrm{S}+3 \mathrm{Ma}$ and $\mathrm{S}+\mathrm{Atg} 7(-)+3 \mathrm{Ma}$ groups, the cell mass died and cell quantity markedly reduced. The cells were not easily observed with the microscope. Furthermore, the cells appeared more round and did not easily adhere to the wall of culture plate following 3Ma treatment (Fig. 2).

$3 M a$ treatment reduces viability of MDA-MB-231 cells while Atg7 deficiency does not. Cell viabilities of all groups at different time points $(6,12,24,48$ and $72 \mathrm{~h})$ were analyzed (Fig. 3). The percentage cell viability was not significantly different between Atg7 siRNA-transfected groups and untransfected groups at any time point $(\mathrm{P}>0.05)$. 3Ma treatment did not significantly affect cell viability at the 6 and $12 \mathrm{~h}$ time points in any groups $(\mathrm{P}>0.05)$. In cells without Atg7 deficiency, the $3 \mathrm{Ma}$ treatment led to significantly reduced viability at 48 and $72 \mathrm{~h}(\mathrm{P}<0.001, \mathrm{~S}$ vs. $\mathrm{S}+3 \mathrm{Ma})$; whilst in Atg7-deficient cells, 3Ma treatment led to a 


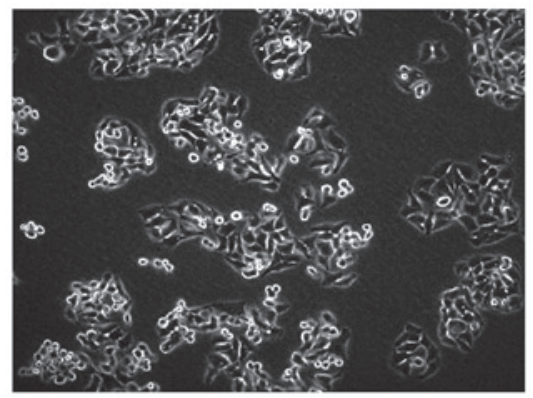

Control

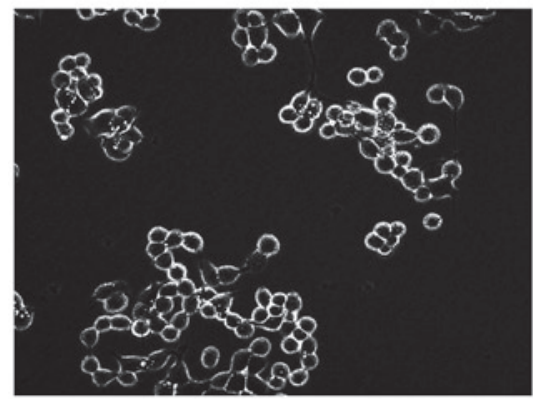

$\mathrm{S}+3 \mathrm{Ma}$

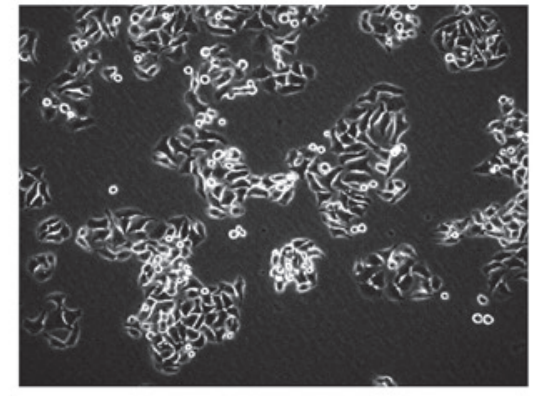

$\operatorname{Atg} 7(-)$

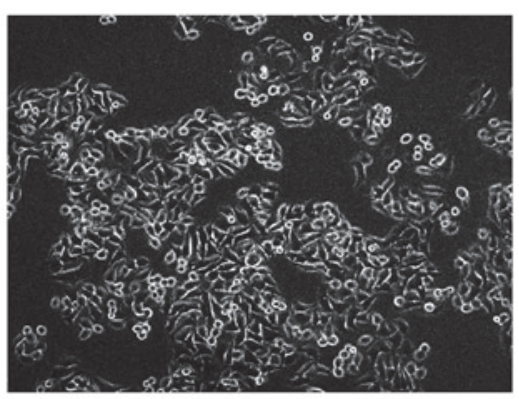

s+Atg7(-)

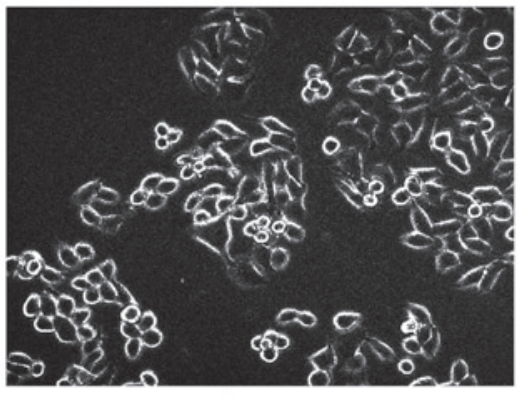

S

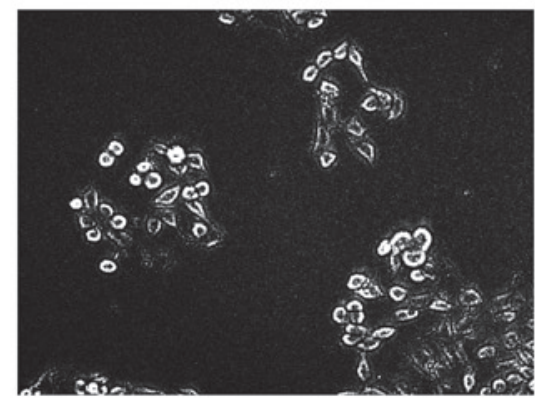

$\mathrm{S}+\operatorname{Atg} 7(-)+3 \mathrm{Ma}$

Figure 2. Cytomorphological changes in groups at the 24-h time point. In the Atg7(-), S+Atg7(-) and S+Atg7(-)+3Ma groups, the cells exhibited more protuberances and congregated or adhered to the wall of culture plate more easily compared with the control, S and S+3Ma groups. Compared with the other groups, in the S+3Ma and S+Atg7(-)+3Ma groups, the cell mass died and the cells appeared more round and did not easily adhere to the wall of culture plate following 3Ma treatment. 3Ma, 3-methyladenine; S, starved; Atg7(-), Atg7 siRNA transfected.

A

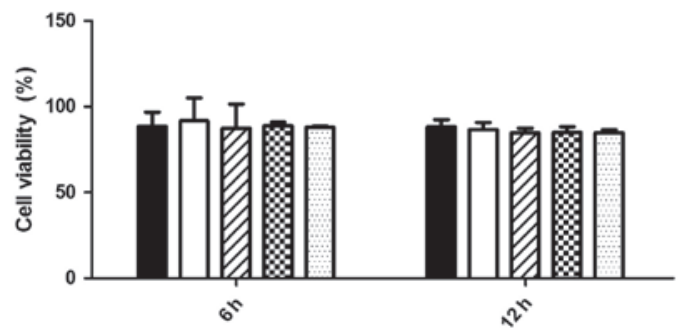

B

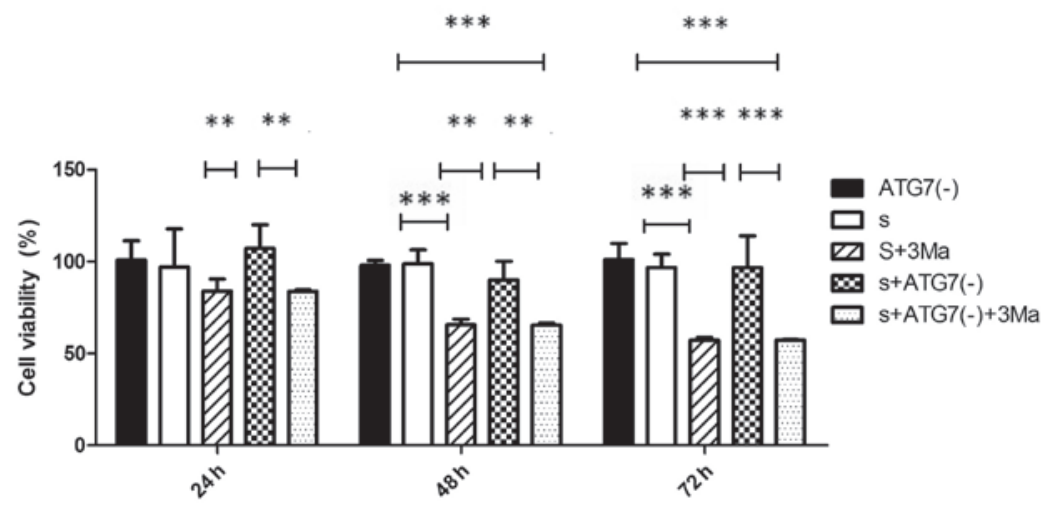

Figure 3. The cell viability of each group at different time points. Cell viabilities in all groups at five time points [(A) 6 and 12 h; (B) 24 , 48 and 72 h] were analyzed by two-way repeated measured analysis of variance with Bonferroni post-hoc tests. Data are expressed as the mean \pm standard deviation of experiments performed in triplicate. Atg7 siRNA transfection did not significantly affect the cell viability of any groups at any time points (P>0.05). $3 \mathrm{Ma}$ did not significantly affect cell viability of any groups at the 6 and $12 \mathrm{~h}$ time points $(\mathrm{P}>0.05)$. In the comparison with the $\mathrm{S}$ group, $3 \mathrm{Ma}$ without Atg7 deficiency reduced the cell viability at 48 and $72 \mathrm{~h}\left({ }^{* * *} \mathrm{P}<0.001\right)$. In the comparison with the S+Atg7(-) group, 3Ma in combination with Atg7 deficiency reduced the cell viability at 24 and $48 \mathrm{~h}\left({ }^{* *} \mathrm{P}<0.01\right)$ and $72 \mathrm{~h}(\mathrm{P}<0.001) .3 \mathrm{Ma}, 3$-methyladenine; S, starved; Atg7(-), Atg7 siRNA transfected.

significant reduction in viability at $24,48(\mathrm{P}<0.01)$ and $72 \mathrm{~h}$ $(\mathrm{P}<0.001)[\mathrm{S}+\mathrm{Atg}(-)$ vs. S+Atg7(-)+3Ma]. When comparing the difference between the effects of Atg7 deficiency and $3 \mathrm{Ma}$ treatment, the $\mathrm{S}+3 \mathrm{Ma}$ group exhibited lower cell viability compared with the S+Atg7(-) group at 24 and $48 \mathrm{~h}$ time points $(\mathrm{P}<0.01)$ and at the $72 \mathrm{~h}$ time point $(\mathrm{P}<0.001)$ (Fig. 3B).

Effects of Atg7 siRNA interference and 3Ma treatment on apoptosis and cell cycle in MDA-MB-231 cells. The cells in the $\mathrm{SubG}_{1}$-phase represent cells undergoing apoptosis
(Fig. 4). Atg7 siRNA transfection led to increased percentages of cells in apoptosis and in the $\mathrm{G}_{0} / \mathrm{G}_{1}$-phase; while the percentage of cells in the $\mathrm{S}$-phase reduced $[\mathrm{P}<0.001, \mathrm{~S}$ vs. $\mathrm{S}+\operatorname{Atg} 7(-)]$. In the untransfected cells, $3 \mathrm{Ma}$ treatment led to an increase in percentage of cells in apoptosis $(\mathrm{P}<0.01)$ and in the $G_{0} / G_{1}$-phase $(P<0.001)$, while the percentage in the $\mathrm{S}$-phase decreased $(\mathrm{P}<0.001)(\mathrm{S}$ vs. $\mathrm{S}+3 \mathrm{Ma})$. However, in the Atg7 deficient cells, 3Ma led to reduced levels of apoptosis and S-phase cells, while there was an increased percentage of cells in the $G_{0} / G_{1}$-phase $[P<0.001, S+A t g 7(-)$ vs. S+Atg7(-)+3Ma]. 



Figure 4. (A) Percentages of cell number in different cell cycle phases. Cells in the $\mathrm{SubG}_{1}$-phase represent the cells undergoing apoptosis. Compared with the groups prior to transfection with Atg7 siRNA, the percentages of cells in apoptosis and $\mathrm{G}_{0} / \mathrm{G}_{1}$-phase were increased in all starvation groups with transfection, while those in the S-phase decreased. This pattern was also observed in the S+3Ma group, in comparison with the S group. However, in the S+Atg7(-)+3Ma group, the percentages of cells in apoptosis and $\mathrm{S}$-phase were reduced, while those in $\mathrm{G}_{0} / \mathrm{G}_{1}$-phase were increased in comparison with the $\mathrm{S}+\mathrm{Atg} 7(-)$ group. ${ }^{* * *} \mathrm{P}<0.001$ and $^{* *} \mathrm{P}<0.01$ calculated with two-way repeated measures analysis of variance in GraphPad Prism version 5.0 software. (B) Flow cytometry maps of each group analyzed by FACSDiva software at $24 \mathrm{~h}$ after transfection of Atg7-siRNA.

\section{Discussion}

Following analysis of the cellular morphology of the groups, autophagy inhibition by Atg7 deficiency functions to maintain the adhesion of MDA-MB-231 cells, however, another autophagy inhibitor, $3 \mathrm{Ma}$, functions to deprive the adhesion of MDA-MB-231 cells.

The results of the cell viability assay indicated that transfection of Atg7-siRNA had no significant effect on the survival of
MDA-MB-231 human breast cancer cells. This result supports those of previous clinical studies. Chang et al (17) reported that the loss of Atg7 or Atg3 function did not influence cellular processes during intestinal cell death and they hypothesized that there is an Atg7- and Atg3-independent autophagy pathway which is used in certain cells. Qin et al (18) systematically screened 14 functional polymorphisms in six autophagy-related genes including Atg7 and identified no association of Atg7 gene variants with the risk of breast cancer in a Chinese population. 
In the current study, the results of the flow cytometry revealed that autophagy inhibition by transfection of Atg7 siRNA increased the percentages of cells in apoptosis and $\mathrm{G}_{0} / \mathrm{G}_{1}$-phase, while it reduced the percentage of cells in $\mathrm{S}$-phase in the starvation groups. The cell cycle was arrested in the $\mathrm{G}_{0} / \mathrm{G}_{1}$-phase. These results support the theory that Atg7 deficiency inhibits proliferation and promotes apoptosis in MDA-MB-231 human breast cancer cells; however, no effect of Atg7 deficiency on cell viability was observed.

The results of the present study imply that the effect of autophagy inhibition by Atg7 deficiency is not sufficient to reduce cell viability, or that there is another pathway that counteracts its effect on cell viability. Thus, the effect of Atg7 in the breast cancer requires further study. Compared with the control cells, the two factors of starvation and Atg7 deficiency each reduced the percentage of cells in apoptosis and $\mathrm{G}_{0} / \mathrm{G}_{1}$-phase and elevated the percentage of cells in S-phase. This implies the effect of Atg7 deficiency on the cell cycle may associate with glucose starvation. The data supports a study by Balmer et al (19) which indicated that low glucose-induced apoptosis with inhibition of autophagy may lead to cell death in $661 \mathrm{~W}$ photoreceptor cells. Ramírez-Peinado et al (20) hypothesized that autophagic flux induced by other stimuli is inhibited in the absence of glucose. Data from the present study suggest the inhibition of autophagy by Atg7 deficiency may promote apoptosis and cell cycle arrest in the $\mathrm{G}_{0} / \mathrm{G}_{1}$-phase under conditions of glucose starvation. Following Atg7 siRNA transfection without the glucose starvation, the percentage of cells in the S-phase increased while those in apoptosis reduced. Further study is required to validate these results, and confirm the lack of effect by Atg7 deficiency on cell viability.

According to the results of the current study, inhibition of autophagy by Atg7 deficiency promotes apoptosis and inhibits cell proliferation in cells maintained in low-glucose medium but does not influence the viability of these cells.

As another method of autophagy inhibition, 3Ma has an opposing functional effect to Atg7 deficiency on the cellular morphology. Treated by $3 \mathrm{Ma}$, the cells became rounder and aggregated less easily. The autophagy inhibitor $3 \mathrm{Ma}$ was found to reduce the viability of breast cancer cells. With Atg7 deficiency, the P-value related to the effect of $3 \mathrm{Ma}$ was larger than that without Atg7 deficiency and was significant at an earlier time point (significant difference at 24-h time point). Therefore, the present study provides reasonable grounds to infer that Atg7 deficiency may potentiate the effect of 3Ma on cell viability (but it may also be counteracted by $3 \mathrm{Ma}$ ). The data from the present study demonstrated that an interaction existed between the method of autophagy inhibition occurring following 3Ma treatment and that occurring in Atg7 deficiency.

A number of studies indicate that $3 \mathrm{Ma}$ (21-23) potentiates the effects of anticarcinogens by inhibiting autophagy and increasing apoptosis. It has been suggested that $3 \mathrm{Ma}$ may be a good therapeutic strategy for use in drug-resistant cancer cells. The current study produced a similar result; $3 \mathrm{Ma}$ increased apoptosis in MDA-MB-231 human breast cancer cells. As an autophagy inhibitor, 3Ma significantly increased the percentage of the cells in apoptosis and the $\mathrm{G}_{0} / \mathrm{G}_{1}$-phase while it reduced the percentage of cells in the S-phase. This effect of $3 \mathrm{Ma}$ on the cell cycle resembled that of Atg7 deficiency, indicating that the two methods of autophagy inhibition by $3 \mathrm{Ma}$ treatment and Atg7 deficiency can each promote apoptosis and cell arrest in the $\mathrm{G}_{0} / \mathrm{G}_{1}$-phase. However, in combination with Atg7 deficiency, 3Ma reduced the effect of Atg7 deficiency alone on apoptosis and cell arrest in $\mathrm{G}_{0} / \mathrm{G}_{1}$-phase. Therefore, 3Ma may abrogate the effect of Atg7 deficiency on the cell cycle to a certain extent; whereas, with regards to cell viability, Atg7 deficiency had no influence and 3Ma treatment led to a significant reduction.

The current study confirmed that $3 \mathrm{Ma}$ treatment or Atg7 deficiency can exert effects on the cell cycle to promote apoptosis and cell arrest in $\mathrm{G}_{0} / \mathrm{G}_{1}$-phase in MDA-MB-231 human breast cancer cells.

In conclusion, the current study indicated an interaction between the mechanism of autophagy inhibition following $3 \mathrm{Ma}$ treatment and that occurring in response to Atg7 deficiency. 3Ma strongly reduced the viability of MDA-MB-231 human breast cancer cells and the effect of $3 \mathrm{Ma}$ was potentiated by Atg7 deficiency. In the present study, the absence of glucose was demonstrated to be important on the effect of Atg7 deficiency on the cell cycle. However, Atg7 deficiency did not cause changes in cell viability. Atg7 deficiency may not be sufficient to reduce the cell viability or it is possible that there is another pathway that counteracts its effect on cell viability. Whether affecting cell viability or the cell cycle, there exists negative interaction between mechanisms occurring in Atg 7 deficiency and those following $3 \mathrm{Ma}$ treatment.

Overall, Atg7 appears to be involved in a different pathway to $3 \mathrm{Ma}$ in the process of autophagy. Inhibition of autophagy may influence cell viability and the cell cycle through different pathways in MDA-MB-231 human breast cancer cells.

\section{Acknowledgements}

The authors thank Liuqi Yang (National Key Laboratory of the West China School of Sichuan University) for providing MDA-MB-231 cells, and Qijie Li for technical assistance in flow cytometry. The current study was supported by the National Natural Science Foundation of China, study code H0815, and was funded by the fostering project of Sichuan province Science and Technology Innovation Seedling Engineering, project number 20132048 and the Health Department of Sichuan province, project number 110328.

\section{References}

1. Ahn JH and Lee M: Autophagy-dependent survival of mutant B-raf melanoma cells selected for resistance to apoptosis induced by inhibitors against oncogenic B-raf. Biomol Ther (Seoul) 21: 114-120, 2013.

2. Guo JY, Karsli-Uzunbas G, Mathew R, Aisner SC, Kamphorst JJ, Strohecker AM, Chen G, Price S, Lu W, Teng X, et al: Autophagy suppresses progression of K-ras-induced lung tumors to oncocytomas and maintains lipid homeostasis. Genes Dev 27: 1447-1461, 2013.

3. Zhu L, Du H, Shi M, Chen Z and Hang J: ATG7 deficiency promote apoptotic death induced by Cisplatin in human esophageal squamous cell carcinoma cells. Bull Cancer 100: 15-21, 2013.

4. Shen J, Zheng H, Ruan J, Fang W, Li A, Tian G, Niu X, Luo S and Zhao P: Autophagy inhibition induces enhanced proapoptotic effects of ZD6474 in glioblastoma. Br J Cancer 109: 164-171, 2013.

5. Tong Y, You L, Liu H, Li L, Meng H, Qian Q and Qian W: Potent antitumor activity of oncolytic adenovirus expressing Beclin-1 via induction of autophagic cell death in leukemia. Oncotarget 4: 860-874, 2013. 
6. Basit F, Cristofanon S and Fulda S: Obatoclax (GX15-070) triggers necroptosis by promoting the assembly of the necrosome on autophagosomal membranes. Cell Death Differ 20: 1161-1173, 2013.

7. Yue W, Hamaï A, Tonelli G, Bauvy C, Nicolas V, Tharinger H, Codogno P and Mehrpour M: Inhibition of the autophagic flux by salinomycin in breast cancer stem-like/progenitor cells interferes with their maintenance. Autophagy 9: 714-729, 2013.

8. Kumar S, Kumar A, Pathania AS, Guru SK, Jada S, Sharma PR, Bhushan S, Saxena AK, Kumar HM and Malik F: Tiron and trolox potentiate the autophagic cell death induced by magnolol analog Ery5 by activation of Bax in HL-60 cells. Apoptosis 18: 605-617, 2013.

9. Park JH, Lee JE, Lee SJ, Park SJ, Park KH, Jeong M and Koh HC: Potential autophagy enhancers protect against fipronil-induced apoptosis in SH-SY5Y cells. Toxicol Lett 223: 25-34, 2013.

10. Qu W, Xiao J, Zhang H, Chen Q, Wang Z, Shi H, Gong L, Chen J, Liu Y, Cao R and Lv J: B19, a novel monocarbonyl analogue of curcumin, induces human ovarian cancer cell apoptosis via activation of endoplasmic reticulum stress and the autophagy signaling pathway. Int J Biol Sci 9: 766-777, 2013.

11. Polewska J, Skwarska A, Augustin E and Konopa J: DNA-damaging imidazoacridinone C-1311 induces autophagy followed by irreversible growth arrest and senescence in human lung cancer cells. J Pharmacol Exp Ther 346: 393-405, 2013.

12. Wei YM, Li X, Xu M, Abais JM, Chen Y, Riebling CR, Boini KM, Li PL and Zhang Y: Enhancement of autophagy by simvastatin through inhibition of Rac1-mTOR signaling pathway in coronary arterial myocytes. Cell Physiol Biochem 31: 925-937, 2013.

13. Ye L, Zhao X, Lu J, Qian G, Zheng JC and Ge S: Knockdown of TIGAR by RNA interference induces apoptosis and autophagy in HepG2 hepatocellular carcinoma cells. Biochem Biophys Res Commun 437: 300-306, 2013.

14. Sheng Y, Sun B, Guo WT, Zhang YH, Liu X, Xing Y and Dong DL: 3-Methyladenine induces cell death and its interaction with chemotherapeutic drugs is independent of autophagy. Biochem Biophys Res Commun 432: 5-9, 2013.
15. Lei FR, Li XQ, Liu H, Zhu RD, Meng QY and Rong JJ: Rapamycin and 3-methyladenine regulate apoptosis and autophagy in bone-derived endothelial progenitor cells. Chin Med J (Engl) 125: 4076-4082, 2012.

16. Lin YC, Kuo HC, Wang JS and Lin WW: Regulation of inflammatory response by 3 -methyladenine involves the coordinative actions on Akt and glycogen synthase kinase $3 \beta$ rather than autophagy. J Immunol 189: 4154-4164, 2012.

17. Chang TK, Shravage BV, Hayes SD, Powers CM, Simin RT, Wade Harper J and Baehrecke EH: Uba1 functions in Atg7- and Atg3-independent autophagy. Nat Cell Biol 15: 1067-1078, 2013.

18. Qin Z, Xue J, He Y, Ma H, Jin G, Chen J, Hu Z, Liu X and Shen H: Potentially functional polymorphisms in ATG10 are associated with risk of breast cancer in a Chinese population. Gene 527 : 491-495, 2013.

19. Balmer D, Emery M, Andreux P, Auwerx J, Ginet V, Puyal J, Schorderet DF and Roduit R: Autophagy defect is associated with low glucose-induced apoptosis in $661 \mathrm{~W}$ photoreceptor cells. PLoS One 8: e74162, 2013.

20. Ramírez-Peinado S, León-Annicchiarico CL, Galindo-Moreno J, Iurlaro R, Caro-Maldonado A, Prehn JH, Ryan KM and Muñoz-Pinedo C: Glucose-starved cells do not engage in prosurvival autophagy. J Biol Chem 288: 30387-30398, 2013.

21. Pliyev BK and Menshikov M: Differential effects of the autophagy inhibitors 3-methyladenine and chloroquine on spontaneous and TNF- $\alpha$-induced neutrophil apoptosis. Apoptosis 17: 1050-1065, 2012.

22. Tseng HC, Liu WS, Tyan YS, Chiang HC, Kuo WH and Chou FP: Sensitizing effect of 3-methyladenine on radiation-induced cytotoxicity in radio-resistant HepG2 cells in vitro and in tumor xenografts. Chem Biol Interact 192: 201-208, 2011.

23. Wu YT, Tan HL, Shui G, Bauvy C, Huang Q, Wenk MR, Ong CN, Codogno P and Shen HM: Dual role of 3-methyladenine in modulation of autophagy via different temporal patterns of inhibition on class I and III phosphoinositide 3-kinase. J Biol Chem 285: 10850-10861, 2010. 